\title{
AH Amyloidosis
}

National Cancer Institute

\section{Source}

National Cancer Institute. AH Amyloidosis. NCI Thesaurus. Code C158962.

A rare type of amyloidosis characterized by the monoclonal deposition of

immunoglobulin heavy chain fragments in organs and tissues. It is associated with plasma cell or B-cell lymphoproliferative disorders. 